\title{
Investigating the Interactive Effect of Card Cylinder Speed and Roller Gauge Settings of Breaker Drawing on Combed Yarn Evenness and Imperfections
}

\author{
Hosne Ara Begum ${ }^{1}$, Md. Saitham Al Sagir Rakine², Shadman Ahmed Khan², \\ Md. Khalilur Rahman Khan ${ }^{2, *}$ \\ ${ }^{1}$ Department of Yarn Engineering, Bangladesh University of Textiles, Dhaka, Bangladesh \\ ${ }^{2}$ Department of Textile Engineering, Bangladesh University of Business and Technology, Dhaka, Bangladesh \\ Email address: \\ rakin2294@gmail.com (Md. S. Al S. Rakine),shadmante26@gmail.com (S. A. Khan), khalilbutex@gmail.com (Md. K. R. Khan) \\ *Corresponding author
}

\section{To cite this article:}

Hosne Ara Begum, Md. Saitham Al Sagir Rakine, Shadman Ahmed Khan, Md. Khalilur Rahman Khan. Investigating the Interactive Effect of Card Cylinder Speed and Roller Gauge Settings of Breaker Drawing on Combed Yarn Evenness and Imperfections. Advances in Applied Sciences. Vol. 4, No. 3, 2019, pp. 72-77. doi: 10.11648/j.aas.20190403.11

Received: May 10, 2019; Accepted: June 12, 2019; Published: July 16, 2019

\begin{abstract}
This project work deals to investigate the interactive impact of cylinder speed and roller gauge setting of breaker drawing frame on ring spun combed yarn evenness and imperfections. In this work, carded slivers were produced by keeping cylinder rpm of $750 \mathrm{rpm}, 800 \mathrm{rpm}$ and $850 \mathrm{rpm}$ while subsequent roller gauge settings (front zone/ back zone) in drawing frame were selected at three levels (i.e., F38mm/B42 mm, F40mm/B44 mm \& F42mm/B46 mm) for each cylinder rpm. Cotton combed yarns of $32 \mathrm{Ne}$ and $36 \mathrm{Ne}$ from roving hank of $0.76 \mathrm{Ne}$ have been produced for each combination of cylinder rpm and roller setting gauge. However, results show that best combination of cylinder rpm and roller gauge settings is found $800 \mathrm{rpm}$ and F40/B44 respectively in terms of yarn evenness and imperfections for both types of yarn count. Moreover, roller gauge settings should be kept somewhat narrower (i.e., Front $38 \mathrm{~mm} /$ Back $42 \mathrm{~mm}$ ) for carded slivers produced at higher cylinder speed (i.e., $850 \mathrm{rpm}$ ), otherwise it is observed that short fiber percentage and $\mathrm{CV}_{1 \mathrm{~m}} \%$ of combed sliver have been increased for the combination of higher cylinder speed with wider roller gauge settings. As a result, final yarn evenness and imperfections results also have been deteriorated. On the other hand, for comparatively lower level of cylinder speed (i.e., $750 \mathrm{rpm}$ ) little wider roller gauge settings of subsequent drawing frame improves evenness and decreases SFC\% of combed sliver and finally it has contributed to improve the combed yarn quality as well. Simultaneously it is also noticeable that comparatively wider roller setting (i.e., F42mm/B46 mm) gives poor results for all three level of cylinder speed. However, for both types of yarn count, results show similar trend in terms of evenness and imperfections but finer yarn count reacts more intensively in comparison with coarser count.
\end{abstract}

Keywords: Cylinder Speed, Roller Gauge Setting, Combed Yarn, Yarn Evenness \& Imperfections

\section{Introduction}

Yarn formation is the process of converting loose fiber into a yarn structure, involving a progression of distinctly different and separate processes. The yarn produced from fibers that have been combed is known as combed yarn [1]. Combing is a process by which quantity of short fibres and remnant fragments of impurities present in a carded or drawn sliver are minimized to give a clean sliver, having more of a rectangular staple diagram, with vast majority of constituent fibres in a straightened and parallel state [2]. However, Quality and cost of production are two important considering parts during production of combed ring spun yarn. The presence of high yarn unevenness and imperfections affect the appearance and strength variation of woven and knitted fabric. Increase in yarn unevenness and imperfections will increase the breakage rate of ring spinning and thereby reduce the productivity. From this perspective, it is important to optimize the processing conditions of spinning preparatory stages such as carding and breaker drawing frame. Otherwise 
faulty feed lap will be produced that is certainly linked with comber noil $\%$ and also with combed yarn quality. The lap sheet with high degree of evenness produces the highly uniform combed sliver. Therefore, good fiber orientation in the feed lap is a prerequisite for obtaining better sliver quality. The uniformity of lap across the width of is highly important for smooth combing operation. If there are too many thick and thin places in the lap, then it will affect the productivity and as well as quality of output sliver [3].

Fiber to yarn conversion process has been affected by several factors which include properties of raw material, level of technology, machinery and skill of machine operators [4]. The complexity of fiber to yarn spinning process and interaction among various spinning conditions is very high.

The fundamental operations of yarn manufacture are carding, drawing, twisting and spinning [5]. Carding is the most vital process in spinning, which influences the sliver quality and the resulting yarn characteristics [6]. The carding quality is primarily determined in the cylinder region [7]. The cylinder wire takes over the fibers from the licker-in and is responsible for the main carding action with the flexible tops [8]. In card, the action of the cylinder is to individualize fibres and to give parallelism to the fibre mass flow. Van Alphen reports that increasing cylinder speed causes more fibre breakage than increasing taker-in speed and that this is reflected in the yarn properties [9]. The higher sensitivity of ring yarns to fibre breakage was attributed to the negative effect of short fibres during roller drafting [10]. On the other hand, exceeding higher cylinder speed can lead to higher neps generation which decreases the quality of card sliver. Fiber hooks those are produced in carding machine influence the effective fiber length or fibre extent. This will affect the drafting performance as well.

After carding process the carded sliver is subjected to drawing and doubling operation. The draw frame in a textile mill is unavoidable in yarn spinning as fibers need to be kept side by side termed as parallelization of fibers in textile technology [11]. Owing to various differences in the technical parameters of drawing machines, their capacity of controlling the fibers during drafting differs considerably, resulting in different natures of added of irregularity of the drafted sliver [12]. Most of the improvement in fiber parallelization and reduction in hooks takes place at first draw frame passage than at second passage [13].

Fiber properties and their interaction with drafting conditions, which determine fiber behavior, affect drafting force, variation in drafting force, and sliver irregularity. Drafting force depends on many factors such as crimp, fiber length, surface characteristics, and friction coefficient as well as draft setting and sliver linear density [14]. Fiber length is a very important physical measure in cotton spinning industry. Yarn quality parameters such as strength, elongation, hairiness, and evenness are strongly correlated to the length of cotton fibers [15]. Drafting is an important process affected due to the length variability [16].

The distance between the nips of the pairs of rollers is commonly referred as the roller setting. Roller setting is one of the very important process parameters in draw frame. Generally, the setting in back zone is little wider than their setting in the front zoning [17]. The roller setting predominantly influences the output sliver quality and process efficiency [18]. When the setting is low, the irregularity may also increase as many fibers will be simultaneously gripped or nipped by both the nips of the drafting rollers and they will be pulled out in the form of a bunch from the back roller nip and hence there is a there is an increase in irregularity. If we increase the setting too much most of the fibers will behave like short fibers. And therefore, they will move in an erratic manner within the drafting zone and as a result there will be increase in irregularity [19]. The effect of floating fiber is to produce a succession of thick and thin places in the output length where some fiber extents have been drafted in the ideal manner. The thick and thin variation has a sinusoidal waveform and is therefore called the drafting wave. The drafting wave gives and irregularity additional to that of the input irregularity [20]. At optimum roller gauge settings, the hook removal is obtained maximum also. Hence, roller settings adjustment based on fiber length distributions of carded sliver would have a great significance.

However, knowledge of the interactions of fiber length properties after carding process for various type of cylinder speed with the understanding of fiber drafting behavior for different roller gauge settings should be perceived in depth before combing operation. Since combing operation is specially destined for producing yarn having minimum imperfections and maximum evenness by removing short fibers and fiber neps those are considered as the main disturbing factors in spinning processes for getting quality yarn, so it demands the study of short fiber formations and $\mathrm{NRE} \%$ in carding at various cylinder speed and also the study of seeking the optimum roller gauge settings accordingly. Otherwise, during combing operations feed lap may contain large amount of short fiber, neps and more importantly uneven lap sheet may produces and that will affects the noil percentage, fiber parallelism, neps amount and irregularity of combed sliver as well. As a result, combed yarn evenness and imperfections will be affected also. For this reason, we have examined the interactive effects of cylinder rpm of card and roller gauge settings on breaker drawing frame on combed yarn evenness and imperfections.

\section{Materials and Methods}

\subsection{Raw Materials and Yarn Sample Preparation}

$100 \%$ cotton fibers of West Africa (Benin) were used to produce ring spun combed yarn of $32 \mathrm{Ne}$ and $36 \mathrm{Ne}$. Quality parameters of raw cotton fibers are given in table $1.100 \%$ cotton combed yarns were produced on Marzoli ring spinning frame. For the yarn samples preparations, Blow room to Ring frame material processed through same machinery conditions as well as settings except two variables i.e., card cylinder speed and draw frame roller gauge setting. Constant 
processing parameters from blow room to comber machine are given in table 2 . The flyer rpm of speed frame and roving hank were 1100 and $0.76 \mathrm{Ne}$ respectively. Spindle rpm of ring frame was maintained $16000 \mathrm{rpm}$ throughout the experiment. However, design plan for this experiment has been given in table 3. Cylinder rpm has been varied in three levels (i.e., 750, 800 and 850) for each three types of roller $\mathrm{mm})$. The settings for the back zone were maintained at Front Zone Setting $+4 \mathrm{~mm}$ in all the cases.

Table 1. Specifications of fiber used.

\begin{tabular}{ll}
\hline Fiber specifications & value \\
\hline Fiber Type & $100 \%$ cotton \\
Fineness & $145 \mathrm{mtex}$ \\
Maturity Ratio & 0.79 \\
Upper quartile length $\left(\mathrm{UQL}_{\mathrm{w}}\right)$ & $29.72 \mathrm{~mm}$ \\
SFC $(\mathrm{w})$ & $11.7 \%$ \\
SFC $(\mathrm{n})$ & $31.4 \%$ \\
Uster 5\% length $(\mathrm{n})$ & $34.86 \mathrm{~mm}$ \\
Fiber neps cnt/g & 184 \\
Nep Size $(\mu \mathrm{m})$ & 668 \\
Seed Coat Nep cnt/g & 16 \\
\hline
\end{tabular}

Table 2. Constant processing parameters of experiment.

\begin{tabular}{lll}
\hline Machine & Parameters & value \\
\hline \multirow{2}{*}{ Blow room } & Cleaning Intensity of Uniclean, Rieter B-12 & 0.4 \\
& Cleaning Intensity of Uniflex, Rieter B-60 & 0.2 \\
& Production/kg & 60 \\
Carding, C60 & Flat speed & $0.33 \mathrm{~m} / \mathrm{min}$ \\
& Licker-in rpm & 1450 \\
& Sliver weight & 78 grain/yard \\
& Breaker sliver weight & 75 grain/yard \\
Breaker draw & Total Doubling & 6 \\
frame, RSB & Total draft & 6.81 \\
D-45 & Break draft & 1.15 \\
& Delivery speed & $500 \mathrm{~m} / \mathrm{min}$ \\
Lap former, & Lap weight & $70 \mathrm{gram} / \mathrm{meter}$ \\
\hline
\end{tabular}
gauges (i.e., $38 \mathrm{~mm} / 42 \mathrm{~mm}, 40 \mathrm{~mm} / 44 \mathrm{~mm}$ and $42 \mathrm{~mm} / 46$

\begin{tabular}{|c|c|c|}
\hline Machine & Parameters & value \\
\hline Unilap & Total doubling & 24 \\
\hline \multirow{3}{*}{$\begin{array}{l}\text { Comber, } \\
\text { E-76 }\end{array}$} & Feed/min & $4.7 \mathrm{~mm}$ \\
\hline & Detachment setting & $11 \mathrm{~mm}$ \\
\hline & Combing cycle/min & 400 \\
\hline Finisher draw & Total Doubling & 6 \\
\hline Frame, RSB & Delivery speed & $500 \mathrm{~m} / \mathrm{min}$ \\
\hline D-22 & Sliver weight & 75 grain/yard \\
\hline
\end{tabular}

\subsection{Testing of Yarn Samples}

Yarn evenness and imperfections results have been tested by UT- 5 at testing speed $400 \mathrm{~m} / \mathrm{min}$. Total IPI $/ 1000 \mathrm{~m}$ was calculated by adding Thin $(-50 \%)$, Thick $(+50 \%)$ and Neps $(+200 \%)$ value. Average results of 10 samples produced for each experiment according to design of this project work have been calculated. It is worth mentioning that AFIS report (given in table 4) of carding input (i.e. card mat), carding output (i.e., card sliver) for each rpm of cylinder have been tested by Uster AFIS-PRO. However, all slivers evenness have been tested by Uster tester-5 and $\mathrm{SFC} \%$ and neps amount have been tested by Uster AFIS-PRO.

Table 3. Design plan of experiment.

\begin{tabular}{lll}
\hline $\begin{array}{l}\text { Experiment } \\
\text { no. }\end{array}$ & $\begin{array}{l}\text { Cylinder Speed } \\
\text { (rpm) }\end{array}$ & $\begin{array}{l}\text { Breaker drawing Roller gauge } \\
\text { (front zone } / \text { back zone in } \mathbf{~ m m} \text { ) }\end{array}$ \\
\hline 01. & 750 & Front/Back=38/42 \\
02. & 800 & Front/Back=38/42 \\
03. & 850 & Front/Back=38/42 \\
04. & 750 & Front/Back=40/44 \\
05. & 800 & Front/Back=40/44 \\
06. & 850 & Front/Back=40/44 \\
07. & 750 & Front/Back=42/46 \\
08. & 800 & Front/Back=42/46 \\
09. & 850 & Front/Back=42/46 \\
\hline
\end{tabular}

Table 4. AFIS report of carding mat and carded sliver.

\begin{tabular}{|c|c|c|c|}
\hline Cylinder rpm & Quality parameters & Card Mat (Input) (Average results) & Card sliver (Output) (Average results) \\
\hline \multirow{6}{*}{750} & Fiber neps (cnt/g) & 347 & 136 \\
\hline & Fiber neps size $(\mu \mathrm{m})$ & 672 & 611 \\
\hline & $\mathrm{SFC}(\mathrm{w})$ & $11.92 \%$ & $12.85 \%$ \\
\hline & $\mathrm{SFC}(\mathrm{n})$ & $31.2 \%$ & $31.9 \%$ \\
\hline & $5 \%$ L (n) & $34.57 \mathrm{~mm}$ & $34.13 \mathrm{~mm}$ \\
\hline & NRE\% & $60.80 \%$ & \\
\hline \multirow{6}{*}{800} & Fiber neps $(\mathrm{cnt} / \mathrm{g})$ & 362 & 117 \\
\hline & Neps size $(\mu \mathrm{m})$ & 680 & 591 \\
\hline & $\mathrm{SFC}(\mathrm{w})$ & $12.1 \%$ & $13.4 \%$ \\
\hline & $\mathrm{SFC}(\mathrm{n})$ & $31.8 \%$ & $32.8 \%$ \\
\hline & $5 \%$ L (n) & $34.27 \mathrm{~mm}$ & $33.77 \mathrm{~mm}$ \\
\hline & NRE\% & $67.67 \%$ & \\
\hline \multirow{6}{*}{850} & Fiber neps (cnt/g) & 358 & 129 \\
\hline & Neps size $(\mu \mathrm{m})$ & 646 & 597 \\
\hline & $\mathrm{SFC}(\mathrm{w})$ & $12.03 \%$ & $13.68 \%$ \\
\hline & $\mathrm{SFC}(\mathrm{n})$ & $32.2 \%$ & $33.6 \%$ \\
\hline & $5 \% \mathrm{~L}(\mathrm{n})$ & $34.09 \mathrm{~mm}$ & $33.34 \mathrm{~mm}$ \\
\hline & NRE $\%$ & $63.94 \%$ & \\
\hline
\end{tabular}


Table 5. Results of sliver U\%, comber waste\%, and AFIS results of combed sliver.

\begin{tabular}{|c|c|c|c|c|c|c|c|c|}
\hline $\begin{array}{l}\text { Cylinder } \\
\text { rpm }\end{array}$ & $\begin{array}{l}\text { Carded sliver } \\
\text { U\% (Avg.) }\end{array}$ & $\begin{array}{l}\text { Breaker drawing Roller } \\
\text { gauge in } \mathbf{m m}\end{array}$ & $\begin{array}{l}\text { Breaker } \\
\text { sliver U\% }\end{array}$ & $\begin{array}{l}\begin{array}{l}\text { Combed } \\
\text { sliver U\% }\end{array} \\
\end{array}$ & $\begin{array}{l}\text { Combed sliver } \\
\mathrm{CV}_{1 \mathrm{~m}} \%\end{array}$ & $\begin{array}{l}\text { Comber } \\
\text { Noil\% } \\
\end{array}$ & $\begin{array}{l}\text { Fiber neps in } \\
\text { combed sliver (cnt/g) }\end{array}$ & $\begin{array}{l}\text { SFC\% } \\
\text { (n) in combed sliver }\end{array}$ \\
\hline \multirow{3}{*}{750} & \multirow{3}{*}{$3.62 \%$} & F38/B42 & $3.26 \%$ & $4.82 \%$ & 1.34 & $11.89 \%$ & 76 & $17.3 \%$ \\
\hline & & F40/B44 & $3.06 \%$ & $3.91 \%$ & 0.98 & $12.10 \%$ & 50 & $15.8 \%$ \\
\hline & & F42/B46 & $3.17 \%$ & $4.08 \%$ & 1.29 & $12.22 \%$ & 67 & $16.4 \%$ \\
\hline \multirow{3}{*}{800} & \multirow{3}{*}{$3.2 \%$} & F38/B42 & $3.08 \%$ & $3.85 \%$ & 1.1 & $11.98 \%$ & 52 & $15.9 \%$ \\
\hline & & F40/B44 & $2.59 \%$ & $3.33 \%$ & 0.84 & $12.02 \%$ & 41 & $14.8 \%$ \\
\hline & & F42/B46 & $2.79 \%$ & $3.62 \%$ & 1.16 & $11.88 \%$ & 57 & $16.1 \%$ \\
\hline \multirow{3}{*}{850} & \multirow{3}{*}{$3.51 \%$} & F38/B42 & $2.92 \%$ & $3.93 \%$ & 1.12 & $12.33 \%$ & 59 & $15.9 \%$ \\
\hline & & F40/B44 & $3.15 \%$ & $4.12 \%$ & 1.25 & $12.18 \%$ & 70 & $16.5 \%$ \\
\hline & & F42/B46 & $3.73 \%$ & $4.70 \%$ & 1.41 & $12.04 \%$ & 76 & $17.1 \%$ \\
\hline
\end{tabular}

\section{Results and Discussions}

The experimental results for all the nine yarn samples are given in Table 6 .

Table 6. Unevenness, Imperfections (Thick+50\%, Thin-50\% and Neps $+200 \%$ ) results of Yarns.

\begin{tabular}{|c|c|c|c|c|c|c|c|c|c|c|c|c|}
\hline \multirow{3}{*}{ Expt. no. } & \multicolumn{4}{|c|}{ Yarn U\% } & \multicolumn{2}{|c|}{ Thin Place/km (-50\%) } & \multicolumn{2}{|c|}{ Thick Place/km (+50\%) } & \multicolumn{2}{|c|}{ Neps/km (+200\%) } & \multicolumn{2}{|c|}{ Total IPI/km } \\
\hline & \multicolumn{2}{|l|}{$32 \mathrm{Ne}$} & \multicolumn{2}{|l|}{$36 \mathrm{Ne}$} & \multirow{2}{*}{$\begin{array}{l}32 \mathrm{Ne} \\
\text { Avg } \\
\end{array}$} & \multirow{2}{*}{$\begin{array}{l}36 \mathrm{Ne} \\
\text { Avg }\end{array}$} & \multirow{2}{*}{$\begin{array}{l}32 \mathrm{Ne} \\
\text { Avg } \\
\end{array}$} & \multirow{2}{*}{$\begin{array}{l}36 \mathrm{Ne} \\
\text { Avg }\end{array}$} & \multirow{2}{*}{$\begin{array}{l}32 \mathrm{Ne} \\
\text { Avg } \\
\end{array}$} & \multirow{2}{*}{$\begin{array}{l}36 \mathrm{Ne} \\
\text { Avg } \\
\end{array}$} & \multirow{2}{*}{$\begin{array}{l}32 \mathrm{Ne} \\
\text { Avg } \\
\end{array}$} & \multirow{2}{*}{$\frac{36 \mathrm{Ne}}{\text { Avg }}$} \\
\hline & Avg & $\mathrm{CV} \%$ & Avg & CV\% & & & & & & & & \\
\hline 01. & 11.02 & 2.6 & 11.63 & 2.5 & 2 & 4 & 33 & 74 & 61 & 70 & 96 & 148 \\
\hline 02. & 9.14 & 1.9 & 10.81 & 2.7 & 0 & 3 & 18 & 44 & 43 & 54 & 61 & 101 \\
\hline 03. & 9.87 & 2.3 & 10.28 & 1.7 & 0 & 2 & 25 & 56 & 59 & 64 & 84 & 122 \\
\hline 04. & 10.14 & 1.7 & 9.85 & 1.4 & 0 & 1 & 21 & 53 & 48 & 66 & 69 & 120 \\
\hline 05. & 8.95 & 1.6 & 9.21 & 1.2 & 0 & 0 & 14 & 37 & 37 & 49 & 51 & 86 \\
\hline 06. & 10.37 & 2.2 & 11.40 & 2.5 & 2 & 3 & 37 & 70 & 65 & 77 & 104 & 150 \\
\hline 07. & 10.75 & 3 & 11.19 & 2.8 & 0 & 0 & 29 & 67 & 50 & 75 & 79 & 142 \\
\hline 08. & 10.44 & 1.5 & 10.64 & 2.2 & 2 & 2 & 34 & 55 & 41 & 58 & 77 & 115 \\
\hline 09. & 11.26 & 2.5 & 11.88 & 2.3 & 5 & 6 & 52 & 79 & 67 & 72 & 124 & 157 \\
\hline
\end{tabular}

\subsection{Yarn Irregularity}

To get maximum yarn evenness the attenuation of fiber strand should be achieved with the minimum variation in its linear density. Since fiber of different lengths will tend to move differently during drafting, this will increase the yarn irregularity\% [21]. Figures 1 and 2 shows that yarn U\% for both $32 \mathrm{Ne}$ and $36 \mathrm{Ne}$ are obtained minimum for the combination of cylinder rpm of 800 and roller gauge setting of F40/B44 while $\mathrm{U} \%$ is obtained maximum for the combination of cylinder rpm of 850 and roller gauge of F42/B46. This can be attributed due to the fact that an increase of cylinder speed will increase short fiber percentage as well. Increased level of short fiber in carded sliver will create drafting wave in breaker drawn sliver certainly because of their uncontrolled movement during drafting. As a result, higher irregularity is obtained in drawn sliver that hinders the combing operations accordingly because irregular lap sheet permits poor combing efficiency. Ultimately, for higher cylinder speed, yarn irregularity has been increased when roller settings are kept wider. Although cylinder rpm 750 generates lower level of short fiber percentage (shown in table 4) but fiber individualization will be lowered also in comparison with that of $800 \mathrm{rpm}$. Optimum fiber individualizations resulted in improved fiber parallization of fiber strand with lower irregularity of sliver. That's why roller gauge setting F40/B44 gives improved results of yarn evenness for $800 \mathrm{rpm}$ compared to cylinder rpm of 750 for both yarn counts. It is also seen that for $750 \mathrm{rpm}$ of cylinder, wider roller setting (F42/B46) deteriorates yarn evenness slightly for both $32 \mathrm{Ne}$ and $36 \mathrm{Ne}$. It can also be happened due to the fact that cylinder rpm of 800 produce more cleaned carded sliver with better fiber individualization with lower level of damaged fiber formation compared to cylinder $\mathrm{rpm}$ of 750. As a result, it is seen in table 5 that for the combination of cylinder rpm of 800 and roller gauge of F40/B44, short fiber content (n) in combed sliver is obtained minimum because of better fiber parallelization in drafting zone of breaker draw frame leads better combing performance that is ultimately attributed to improved fiber length uniformity in combed sliver by removing short fiber. Among three types of roller gauge settings, it can be mentioned that roller settings F40/B44 gives best results compared to other two settings. Simultaneously, it should also be stated that higher cylinder speed (i.e., $850 \mathrm{rpm}$ ) lowers the value of 5\% span length of fibers (shown in table 4). As a result, lower roller gauge setting (F38/B42) gives better results of yarn evenness for $850 \mathrm{rpm}$ of cylinder. However, roller gauge setting F40/B44 gives improved results of yarn evenness for both $800 \mathrm{rpm}$ and $750 \mathrm{rpm}$ for both types of yarn count. 


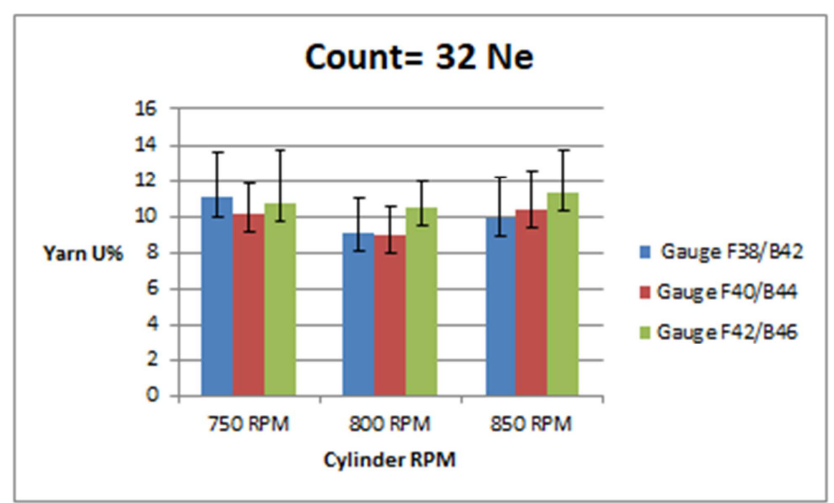

Figure 1. Effect of cylinder speed and roller gauge on Yarn U\% (Count $=32$ $\mathrm{Ne}$.



Figure 2. Effect of cylinder speed and roller gauge on Yarn U\% (Count $=36$ $\mathrm{Ne}$ ).

\subsection{Yarn Imperfections}

Yarn faults in the shape of thin places, thick places, and neps which are called the imperfections are decisive on the external appearance of yarns and the products obtained from them [22].

Figure 3 and 4 show that when cylinder rpm is kept 800 , yarn imperfections (IPI value per $\mathrm{km}$ ) for both yarn count (i.e., $32 \mathrm{Ne}$ and $36 \mathrm{Ne}$ ) reduces distinguishably for all three types of roller gauge setting compared to other two cylinder rpm of 750 and 850. It may be occurred due to higher level of $\mathrm{NRE} \%$ and better individualization of fibers with lower level of hooked fiber formations by cylinder wire in card. Although cylinder rpm of 850 produced low level of hooked fiber due to high cylinder speed but simultaneously short fiber and neps formation tendencies are also high in this case. On the other hand, cylinder rpm of 750 creates somewhat lower amount of short fiber but NRE\% (shown in table 4) is also lower for $750 \mathrm{rpm}$. It is also worth mentioning that poor individualization of fibers is happened and tendency of trailing hooked fiber formation is higher due to lower level of cylinder rpm of 750. These negative two phenomena outweigh the positive effect created by $750 \mathrm{rpm}$ in carded sliver. However, from the results of figures $3 \& 4$, it is observed that $5 \%$ span length of carded sliver is maximum for $750 \mathrm{rpm}$ and minimum for $850 \mathrm{rpm}$ (shown in table 4). From this perspective, optimum roller gauge settings are
F40/B44 and F38/B42 for $750 \mathrm{rpm}$ and $850 \mathrm{rpm}$ respectively in this experiment. It is also noticeable that fibers treated at roller gauge of F40/B44 with cylinder speed of $800 \mathrm{rpm}$ gives better improvement in term of yarn imperfections for both types of yarn count. In table 5 , it is seen that neps ( $\mathrm{cnt} / \mathrm{g}$ ) and SFC\% in combed sliver is obtained minimum for the combination of cylinder rpm 800 and roller gauge of F40/B44. This positive effects may be incorporated in sliver and ultimately in combed yarn because of better combing performances that is mainly linked with decreasing NRE\% and increasing fiber length uniformity of card sliver and subsequently better evenness of breaker sliver as well.

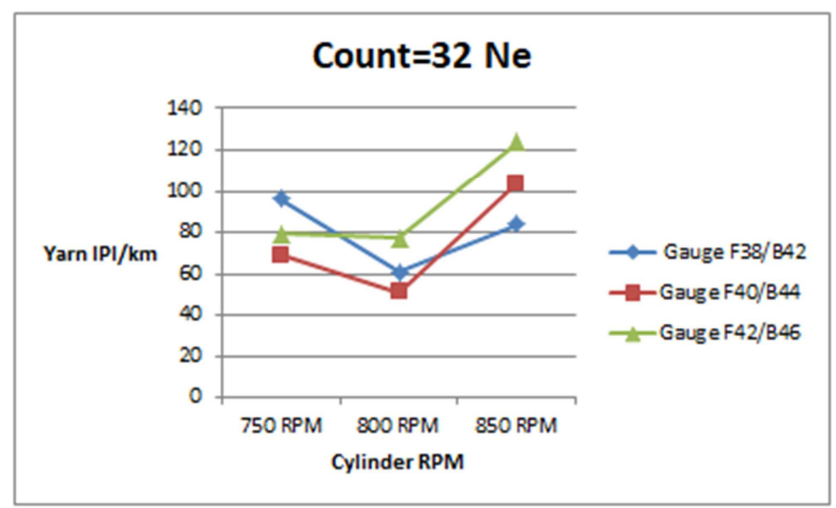

Figure 3. Effect of cylinder speed and roller gauge on Yarn Imperfections (Count=32 Ne).

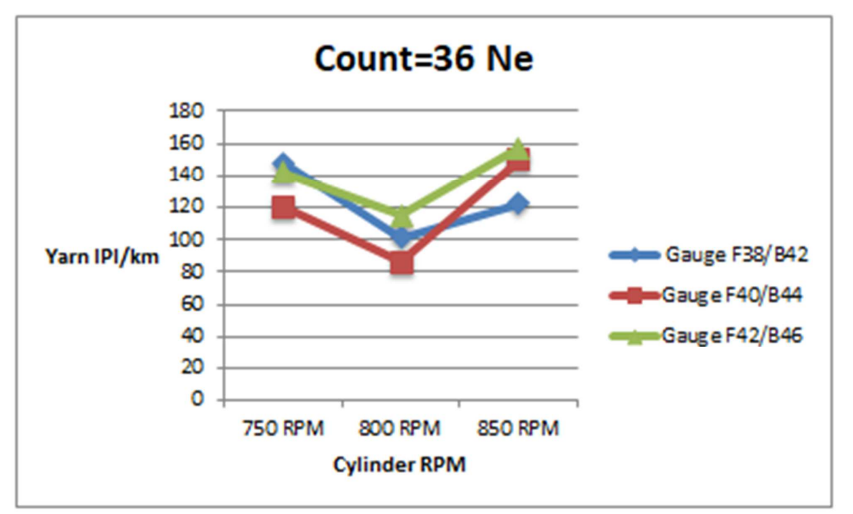

Figure 4. Effect of cylinder speed and roller gauge on Yarn Imperfections $($ Count $=36 \mathrm{Ne}$ ).

\section{Conclusions}

The presented work demonstrated the dependency of ring spun combed yarn quality in terms of evenness and imperfections on variations of cylinder rpm and roller gauge settings of breaker drawing frame. However, it may be concluded that for combed ring spun yarn produced with comparatively higher cylinder speed (i.e., $850 \mathrm{rpm}$ ) roller settings of breaker drawing frame should be kept somewhat narrower (i.e., Front $38 \mathrm{~mm} /$ Back $42 \mathrm{~mm}$ ) otherwise short fiber percentage and $\mathrm{CV}_{1 \mathrm{~m}} \%$ of combed sliver will be higher. As results, it is noticeable that combed yarn of both $32 \mathrm{Ne}$ and $36 \mathrm{Ne}$ produced with higher cylinder speed and wider roller gauge setting shows deterioration of quality in terms of 
evenness and imperfections. It also be concluded that for lower level of cylinder speed (i.e., $750 \mathrm{rpm}$ ) roller gauge settings of subsequent drawing frame should be kept little wider for better evenness at combed sliver and finally at combed yarn as well. Simultaneously, it is also mentionable that much wider settings in drawing frame for any types of cylinder rpm gives poor results in terms of combed yarn evenness and imperfections. Quality parameters of finer combed yarn (i.e., $36 \mathrm{Ne}$ ) react similarly but more sensitively in comparison with a little coarser yarn (i.e., $32 \mathrm{Ne}$ ) because of not selecting optimum roller gauge setting as per cylinder speed in general. Finally, in this experiment, best combination of cylinder rpm and roller gauge settings is found $800 \mathrm{rpm}$ and F40/B44 (Front zone/Back zone $=40 \mathrm{~mm} /$ $44 \mathrm{~mm}$ ) respectively for producing combed spun yarn.

\section{References}

[1] Effects of Carded and Combed Yarn on Pilling and Abrasion Resistance of Single Jersey Knit Fabric, Ayesha Siddika, Md. Nasir Uddin, Mohammad Abdul Jalil, Nur Nahar Akter, Kowshik Saha, OSR Journal of Polymer and Textile Engineering (IOSR-JPTE), Volume 4, Issue 2 (Mar. -Apr. 2017), PP 39-43.

[2] To study effect of comber noil percentage on yarn quality. BaviskarDipali, P. P. Raichurkar, S. P. Bandopadhyay, Ashok Akade, \&P. M. Pachhade, May 2011. Available from: https://www.researchgate.net/publication/277716483_To_stud y_effect_of_comber_noil_percentage_on_yarn_quality [accessed Apr 06 2019].

[3] Process Management in Spinning, R. Senthil Kumar, Page115, CRC press 2015.

[4] J. Ochola, J. Kisato, L. Kinuthia, J. Mwasiagi and A. Waithaka, 2012. Study on the Influence of Fiber Properties on Yarn Imperfections in Ring Spun Yarns. Asian Journal of Textile, 2: 32-43.

[5] The transfer of fibres in the carding machine, M. E. M. Lee and H. Ockendon, Journal of Engineering Mathematics (2006), DOI 10.1007/s10665-005-9029-7.

[6] A Study on the Effect of Pin Density on Stationary Flats and its Setting on Carding Quality, MadanLalRegar, NiharikaAikat, Tekstilec, 2017, 60 (1), 58-64 DOI: 10.14502/Tekstilec2017.60.58-64.

[7] A Study on the Eff ect of Pin Density on Stationary Flats and its Setting on Carding Quality, Madan Lal Regar, Niharika


10.14502/Tekstilec2017.60.58-64.

[8] https://www.grozbeckert.com/mm/media/en/web/pdf/Card_cl othing_for_short_staple_applications.pdf

[9] Van Alphen, W. F. The Card as a Dedusting Machine, Melliand Textilberichte [English Edition], (12), E1523 E1528 / 980 - 984 (1980).

[10] Fibre Dynamics in the Revolving-Flats Card Part I A Critical Review, C. A. Lawrence, A. Dehghani, M. Mahmoudi, B. Greenwood and C. Iype, AUTEX Research Journal, Vol 1, No. 2 November 2000.

[11] Effect of Draw Frame Bottom Roller Gauge Setting on Yarn Quality, Vijay Chaudhari, P. P. Raichurkar, International Journal on Textile Engineering and Processes, Vol. 2, Issue 2 April 2016.

[12] Drafting of Jute: Part-I- Effect of draft on irregularity of drawing slivers, U Datta, S C Bhadra, S Palit, Indian Journal of Textile Research, volume 13, June 198, Pp. 80-83.

[13] http://textiletechinfo.com/spinning/processpardrawing.htm

[14] Relationship between fiber fineness, break draft and drafting force in roller drafting, Yasemin Aydogmus Kori Muz and Hassan M. Behery, Textile res. J. 74 (5), 405-408, 2004.

[15] Generation of Length Distribution, Length Diagram, Fibrogram, and Statistical Characteristics by Weight of Cotton Blends, B. Azzouz, M. Ben Hassen, and F. Sakli, Hindawi Publishing Corporation Modelling and Simulation in Engineering Volume 2007, Article ID 27521, 13 pages.

[16] Optimisation of Draw Frame Roller Settings Using Fibre Length Information From Premier aQura ${ }^{\mathrm{TM}}$, V. Srinivasan, https://www.fibre2fashion.com/industryarticle/2070/optimisation-of-draw-frame-roller-settings

[17] http://textofvideo.nptel.ac.in/116102048/lec18.pdf

[18] Process Management in Spinning, R. Senthil Kumar, Page108, CRC press 2015.

[19] http://textofvideo.nptel.ac.in/116102048/lec18.pdf

[20] Fundamentals of Spun Yarn Technology, Carl A. Lawrence, Page-224, CRC press 2003.

[21] R H Gong and R M Wright, "Fancy Yarns: Their Manufacture and Application", Woodhead Publishing, 2002, pp. 64.

[22] Predicting Yarn Quality Performance Based on Fibers types and Yarn Structure, N. A. Kotb, Life Science Journal 2012; 9 (3). 